\title{
Perbaikan Struktur Bangunan Pasca Gempa dengan menggunakan Serat Karbon (Studi Kasus Gedung Kantor Bea dan Cukai Teluk Bayur Padang)
}

\section{Repair with Post-Earthquake Building Structure using Carbon Fiber Office Building Case Study \\ Customs and Excise Teluk Bayur Padang}

\author{
Elvi Roza Syofyan \\ Jurusan Teknik Sipil Politeknik Negeri Padang Kampus Limau Manis Padang \\ Telp. 0751-72590 Fax.0751-72576 Email: syofyan_er@yahoo.co.id
}

\begin{abstract}
In the last ten years, the area west coast of Sumatra island has several times experienced the earthquake with strong intensity. Starting from the earthquake in Aceh December 26, 2004 until 30 September 2009 earthquake Pariaman ago. The last earthquake measuring 7.9 on the Richter scale has killed more than 1,000 people and damaged buildings 279 432, with 50 percent of them were severely damaged. Another alternative that is better than doing demolition is to retrofit. In general, the retrofit can be described as the addition of new technology or new technology on a merger between the old system (which already exists). In other words, the retrofit is the process of retrofitting old buildings with the aim of making these buildings resistant to earthquakes. From the calculation and analysis conducted on the carbon material, the material Sika Wrap Hex $230 C$ can be used to retrofit House Office Building Customs Bayur Gulf of Padang. The method of implementation should be properly cared for, so that the strength of the building is expected back as they are resistant to earthquakes. It should be noted once in choosing the method of retrofitting that we will use.
\end{abstract}

Keywords: retrofit, Sika Wrap Hex 230C, carbon fiber

\section{PENDAHULUAN}

Dalam sepuluh tahun terakhir, daerah pantai Barat Pulau Sumatera telah beberapa kali mengalami goncangan gempa dengan intensitas kuat. Dimulai dari gempa Aceh 26 Desember 2004 hingga gempa Pariaman 30 September 2009 lalu. Gempa terakhir yang berkekuatan 7.9 skala Richter telah menewaskan lebih dari 1.000 jiwa dan merusak 279.432 bangunan, dengan 50 persen di antaranya rusak berat.

Sebagian besar dari bangunan tersebut mengalami kerusakan berat, namun tidak roboh. Untuk menangani bangunan yang rusak berat tersebut, perobohan bangunan merupakan alternatif yang paling sering diambil. Hal ini keliru. Tidak semua bangunan yang rusak akibat gempa harus dirobohkan. Perlu dilakukan analisis struktur terlebih dahulu sebelum bangunan diputuskan untuk dirobohkan. Bahkan sebenarnya banyak dari bangunan tersebut yang hanya perlu diperbaiki dan diperkuat saja pada bagian-bagiannya yang rusak, tanpa harus dirobohkan.

Banyak yang belum tahu, sebenarnya sudah ada ilmu untuk mengevaluasi bangunan yang rusak akibat gempa. Ilmu ini dapat mengidentifikasi bagian yang rusak serta faktor-faktor penyebabnya, seperti akibat gaya tarik, gaya tekan, dan gaya geser pada bagian-bagian bangunan yang mengalami kerusakan. Selain itu, sudah tersedia perangkat lunak untuk mendukung kegiatan itu, sehingga kerusakan dapat diidentifikasi, baik itu pada bagian struktur bangunan, maupun kerusakan pada dinding bangunan.

Alternatif lain yang lebih baik dibandingkan dengan melakukan penghancuran adalah melakukan retrofit. Secara umum, retrofit bisa dijelaskan sebagai penambahan teknologi baru atau penggabungan antara teknologi baru pada 
sistem yang lama (yang sudah ada). Dengan kata lain, retrofit merupakan proses perkuatan bangunan lama dengan tujuan menjadikan bangunan tersebut tahan terhadap gempa. Penggunaan ilmu ini akan menghemat biaya dan lebih efisien dalam penggunaan tenaga kerja.

Untuk mendapatkan hasil perbaikan dan perkuatan yang tepat guna dan mencapai sasaran yang telah ditetapkan, maka perlu dilakukan investigasi untuk mendapatkan data-data kerusakan baik melalui pengamatan visual ataupun dengan bantuan pengujian non-destructive maupun semi destructive dan mereview dokumen dari struktur yang ada. Dari hasil investigasi tersebut, kemudian dilakukan analisa dan evaluasi pada struktur tersebut untuk menetapkan apakah kerusakan yang terjadi hanya perlu perbaikan atau perlu perkuatan atau dalam kondisi yang terjelek struktur yang mengalami kerusakan harus dilakukan pembongkaran dan dibangun struktur baru.

\section{METODOLOGI}

Dalam pemilihan metode perkuatan, harus diperhatikan beberapa hal yaitu kapasitas struktur, lingkungan dimana struktur berada, peralatan yang tersedia, kemampuan tenaga pelaksana serta batasanbatasan dari pemilik seperti keterbatasan ruang kerja, kemudahan pelaksanaan, waktu pelaksanaan dan biaya perkuatan.

Metode perkuatan yang umumnya dilakukan adalah :

\section{Memperpendek bentang dari struktur dengan konstruksi beton ataupun dengan konstruksi baja.}

Tujuannya adalah memperkecil gayagaya dalam yang terjadi, tetapi harus dianalisa ulang akibat dari perpendekan bentang ini yang menyebabkan perubahan dari gaya-gaya dalam tersebut.

Umumnya dilakukan dengan menambah balok atau kolom baik dari beton maupun dari baja.

\section{Memperbesar dimensi daripada konstruksi beton.}

Umumnya digunakan beton sebagai material untuk memperbesar dimensi struktur; dengan adanya admixture beton generasi baru, dimungkinkan untuk menghasilkan beton yang dapat memadat sendiri (self compacting concrete), dibahas di bagian 4 - Self Compacting Concrete. Akibat dari penambahan dimensi tersebut, maka harus diperhatikan bahwa secara keseluruhan beban dari Bangunan tersebut bertambah, sehingga harus dilakukan analisa secara menyeluruh dari struktur atas sampai pondasi.

\section{Menambah plat baja.}

Tujuan dari penambahan ini adalah untuk menambah kekuatan pada bagian tarik dari struktur Bangunan.

Didalam penambahan plat baja tersebut, harus dijamin bahwa plat baja menjadi satu kesatuan dengan struktur yang ada, umumnya untuk menjamin lekatan antara plat baja dengan struktur beton digunakan epoxy adhesive.

\section{Melakukan external prestressing.}

Dengan metode ini, kapasitas struktur ditingkatkan dengan melakukan prestress di luar struktur, bukan didalam seperti pada struktur baru.

Yang perlu diperhatikan adalah penempatan anchor head, sehingga tidak menyebabkan perlemahan pada struktur yangada. Material yang umumnya digunakan adalah baja prestress, tetapi pada saat ini sudah mulai digunakan bahan dari FRP (Fibre Reinforced Polymer).

\section{Menggunakan FRP (Fibre Reinforced Polymer).}

Prinsip daripada penambahan FRP sama seperti penambahan plat baja, yaitu menambah kekuatan di bagian tarik dari struktur.

Tipe FRP yang sering dipakai pada perkuatan struktur adalah dari bahan carbon, Caramid dan glass. Bentuk FRP yang sering digunakan pada perkuatan 
struktur adalah Plate / Composite dan Fabric / Wrap.

Bentuk plate lebih efektif dan efisien untuk perkuatan lentur baik pada balok maupun plat serta pada dinding; sedang bentuk wrap lebih efektif dan efisien untuk perkuatan geser pada balok serta untuk meningkatkan kapasitas beban axial dan geser pada kolom.

\section{HASIL}

\section{Hasil Pemeriksaan Visual}

a. Denah balok yang akan diperkuat.

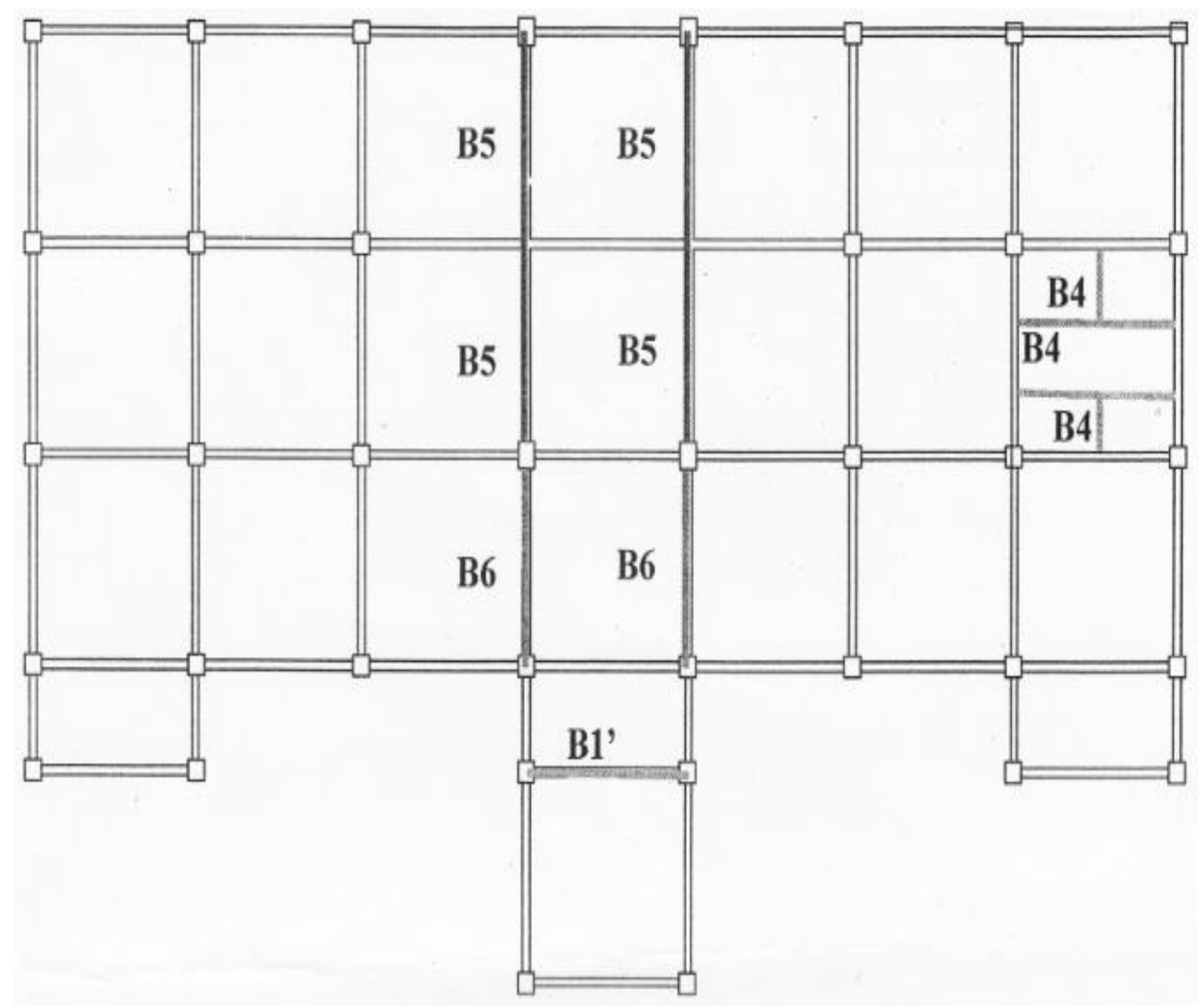

Gambar 1. Denah balok yang akan diperkuat 
b. Data-data balok existing

Tabel 1. Data balok existing dan hasil rekomendasi

\begin{tabular}{|l|c|c|c|c|}
\hline \multirow{2}{*}{ Balok B-1' (25/110) } & \multicolumn{2}{|c|}{ Existing } & \multicolumn{2}{c|}{ Hasil Rekomendasi } \\
\cline { 2 - 5 } & Tumpuan & Lapangan & Tumpuan & Lapangan \\
\hline Tulangan Tekan & 5D19 & 3D19 & 4D19 & 4D19 \\
\hline Tulangan Tarik & 3D19 & 5D19 & 4D19 & 4D19 \\
\hline
\end{tabular}

\begin{tabular}{|l|c|c|c|c|}
\hline \multirow{2}{*}{ Balok B4 (15/25) } & \multicolumn{2}{|c|}{ Existing } & \multicolumn{2}{c|}{ Existing } \\
\cline { 2 - 5 } & Tumpuan & Lapangan & Tumpuan & Lapangan \\
\hline Tulangan Tekan & 2D13 & 2D13 & 3D13 & 2D13 \\
\hline Tulangan Tarik & 2D13 & 2D13 & 2D13 & 2D13 \\
\hline
\end{tabular}

\begin{tabular}{|l|c|c|c|c|}
\hline \multirow{2}{*}{ Balok B5 (40/90) } & \multicolumn{2}{|c|}{ Existing } & \multicolumn{2}{c|}{ Existing } \\
\cline { 2 - 5 } & Tumpuan & Lapangan & Tumpuan & Lapangan \\
\hline Tulangan Tekan & 10D19 & 7D19 & 12D19 & 6D19 \\
\hline Tulangan Tarik & 7D19 & 10D19 & 9D19 & 6D19 \\
\hline
\end{tabular}

\begin{tabular}{|l|c|c|c|c|}
\hline \multirow{2}{*}{ Balok B6(40/60) } & \multicolumn{2}{c|}{ Existing } & \multicolumn{2}{c|}{ Existing } \\
\cline { 2 - 5 } & Tumpuan & Lapangan & Tumpuan & Lapangan \\
\hline Tulangan Tekan & 5D19 & 3D19 & 5D19 & 4D19 \\
\hline Tulangan Tarik & 3D19 & 5D19 & 5D19 & 4D19 \\
\hline
\end{tabular}

\section{PEMBAHASAN}

\section{Perhitungan Perkuatan Balok menggunakan serat karbon}

Spesifikasi teknis Sika Wrap Hex 230C

- Elastis Modulus (N/mm²) 230.000

- Tensile strength $\left(\mathrm{N} / \mathrm{mm}^{2}\right)>3.500$

- Strain $(\%)>1.5$

- Thickness (mm) 0.13

- Width (mm) 600

\section{Balok B5 (40/90)}

Rekomendasi penambahan kekuatan :

Tumpuan: (tarik 7D19 $\rightarrow$ 9D10) (tekan 10D19 $\rightarrow$ 12D10)

Lapangan : Ok

Mutu baja : fy $=390 \mathrm{MPa}$

Tegangan baja tambahan yang diperlukan:

Kondisi tarik $=$ Ast $\mathrm{x}$ fy

$$
\begin{aligned}
& =\left(2 \times \pi \mathrm{D}^{2} / 4\right) \times 390 \\
& =221.240 \mathrm{~N}
\end{aligned}
$$

Usulan perkuatan dengan serat karbon :

Luas penampang serat karbon :

$(400+200) \mathrm{mm} \times 0,130 \mathrm{~mm}=78,00 \mathrm{~mm}^{2}$

Luas penampang serat karbon :
$221.240 \mathrm{~N} / 78,00 \mathrm{~mm}^{2}=2.836 \mathrm{~N} / \mathrm{mm}^{2}$ fy izin $=3.500 \mathrm{~N} / \mathrm{mm}^{2}>$ fy perlu $2.208 \mathrm{~N} /$ $\mathrm{mm}^{2} \rightarrow$ serat karbon setara Sika Wrap Hex 230C dapat digunakan.

\section{Metoda pelaksanaan}

1. Persiapan permukaan (gambar 3)

- Semua material finishing harus dihilangkan dari permukaan beton.

- Permukaan beton yang tidak rata harus diratakan dengan mesin gerinda

- Permukaan beton yang berlubang harus diisi dengan material comention non srink.

2. Pencampuran Epoxy ( gambar 2 )

- Kelembaban dan suhu Typo Epoxy $S$ pada saat pencampuran adalah $10^{\circ} \mathrm{C}$ dan $38^{\circ} \mathrm{C}$.

- Komponen Typo Epoxy $S$ harus dicampur dengan proporsi Parts A : Part B : $100: 34,5$ diaduk dengan mixer berkecepatan rendah selama 3 -5 menit. 

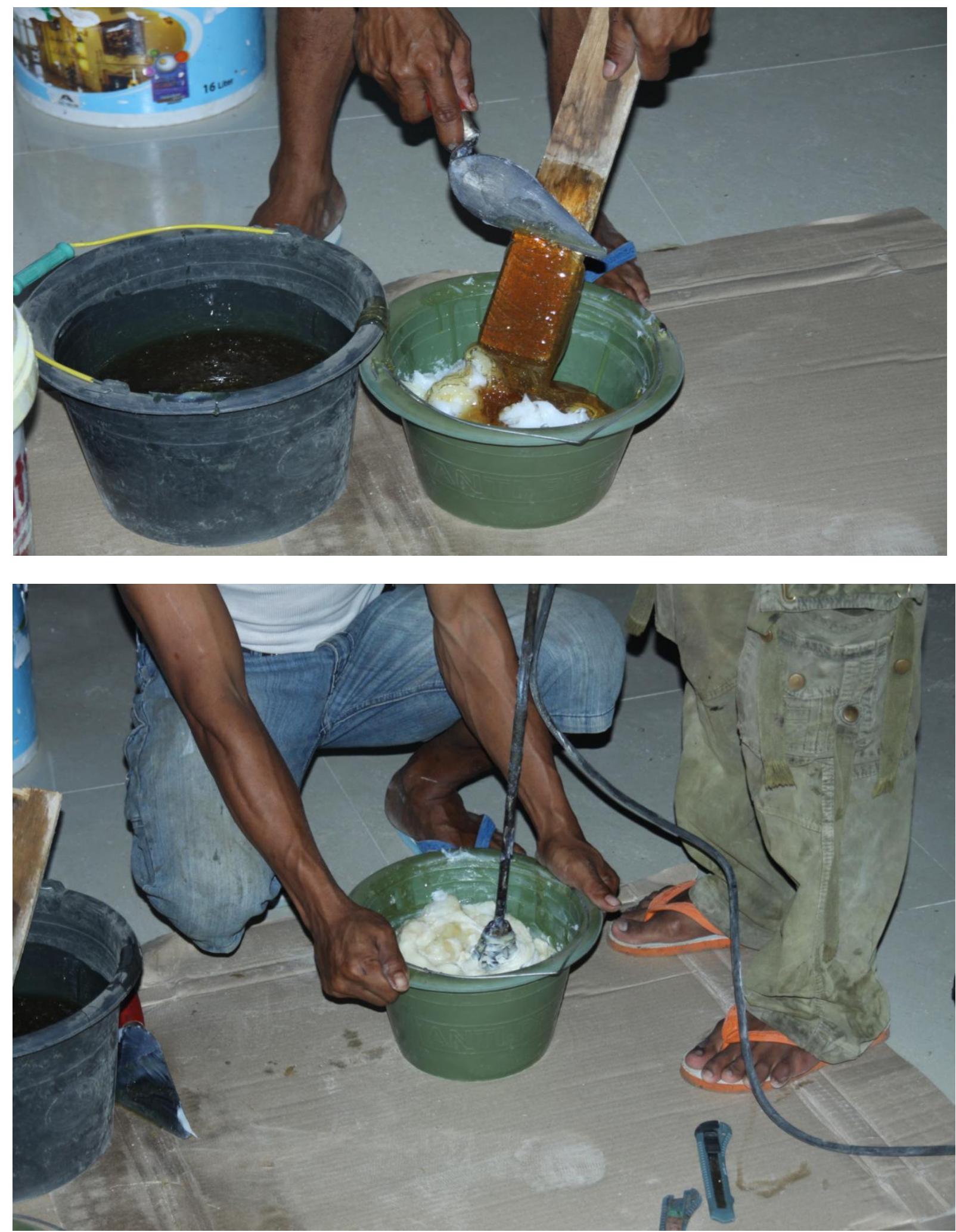

Gambar 2. Pencampuran Epoxy

3. Priming Permukaan beton ( gambar 3 )

- Priming seluruh permukaan beton dengan Typo Epoxy S. 

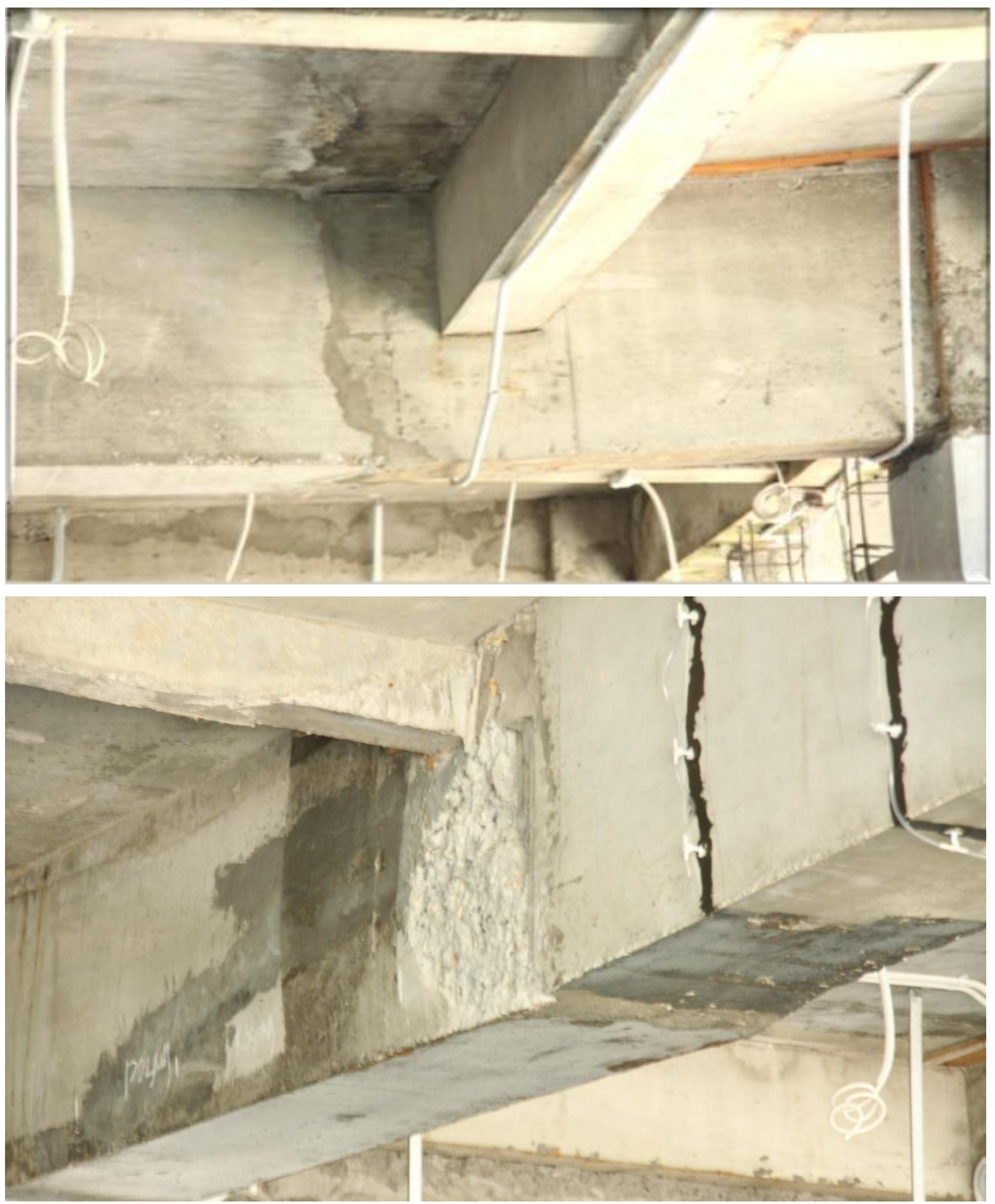

Gambar 3. Priming permukaan beton

4. Saturasi Sika Wrap Hex 230C ( gambar 4 )

- Potong lembaran Sika Wrap Hex 230C sesuai dengan kebutuhan permukaan beton yang akan diperkuat.

- Saturasi antara Sika Wrap Hex 230C dengan Typo Epoxy S harus dilakukan secara dan terukur dan Sika Wrap Hex 230C yang sudah dibasahi dengan Typo Epoxy S harus ditempatkan ditempat khusus. 

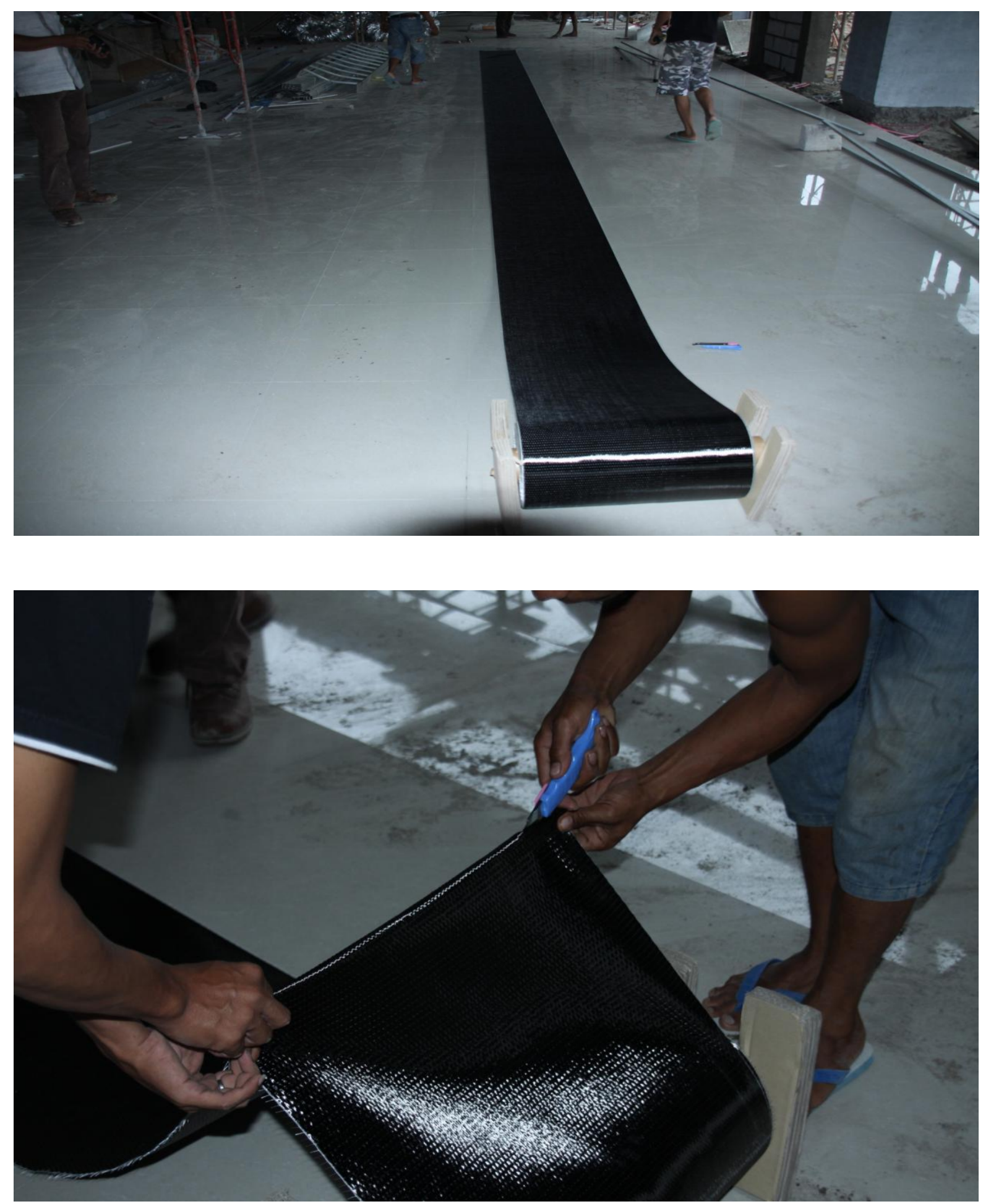

Gambar 4. Saturasi Sika Wrap Hex 230C

5. Wrapping Sika Wrap Hex 230C permukaan beton ( gambar 5 )

- Sika Wrap Hex 230C yang sudah disaturasi dengan Typo Epoxy S diwrapping layer perlayer pada permukaan beton yang sudah dipriming lebih dahulu dengan Typo Epoxy S. 

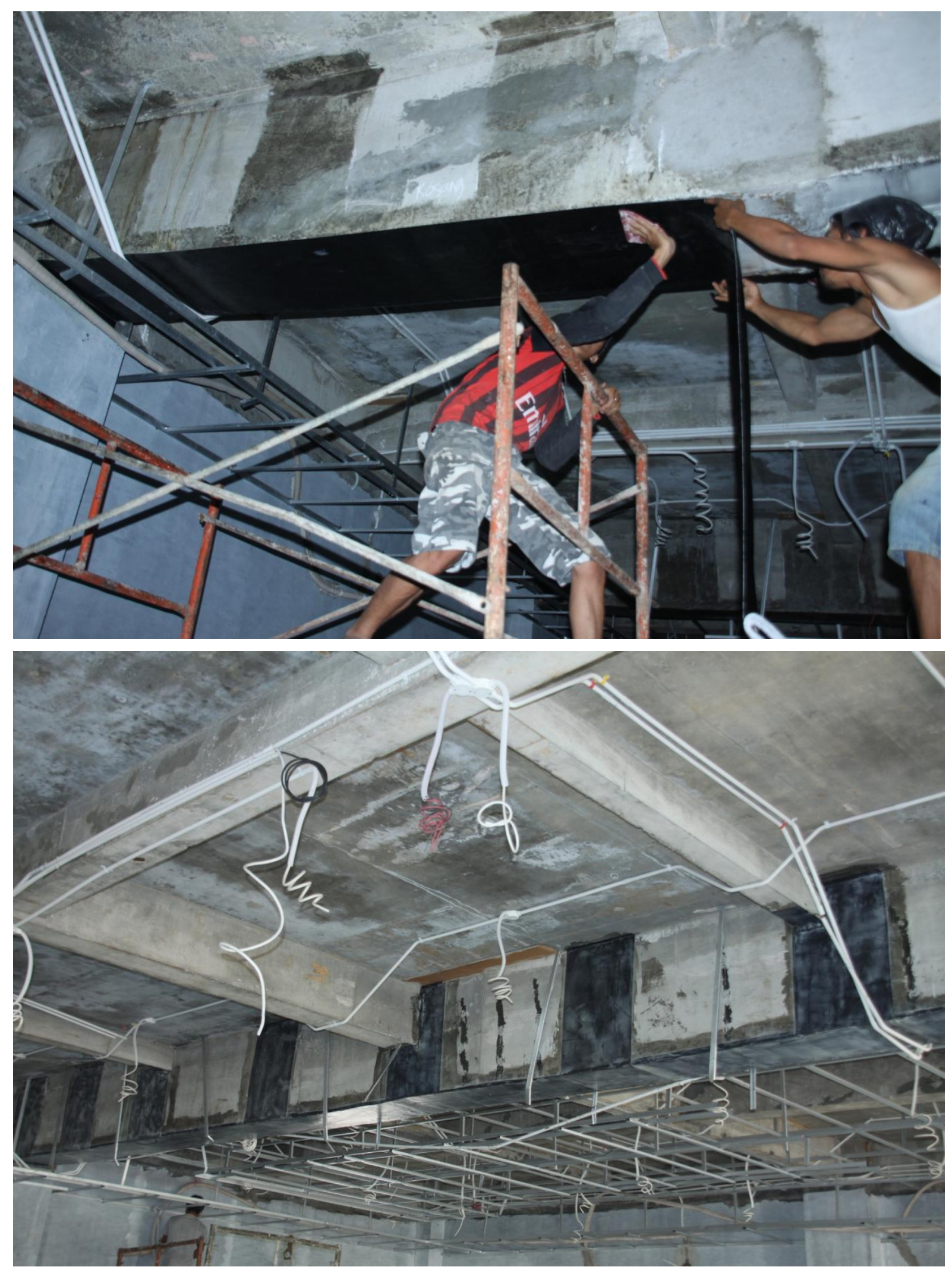


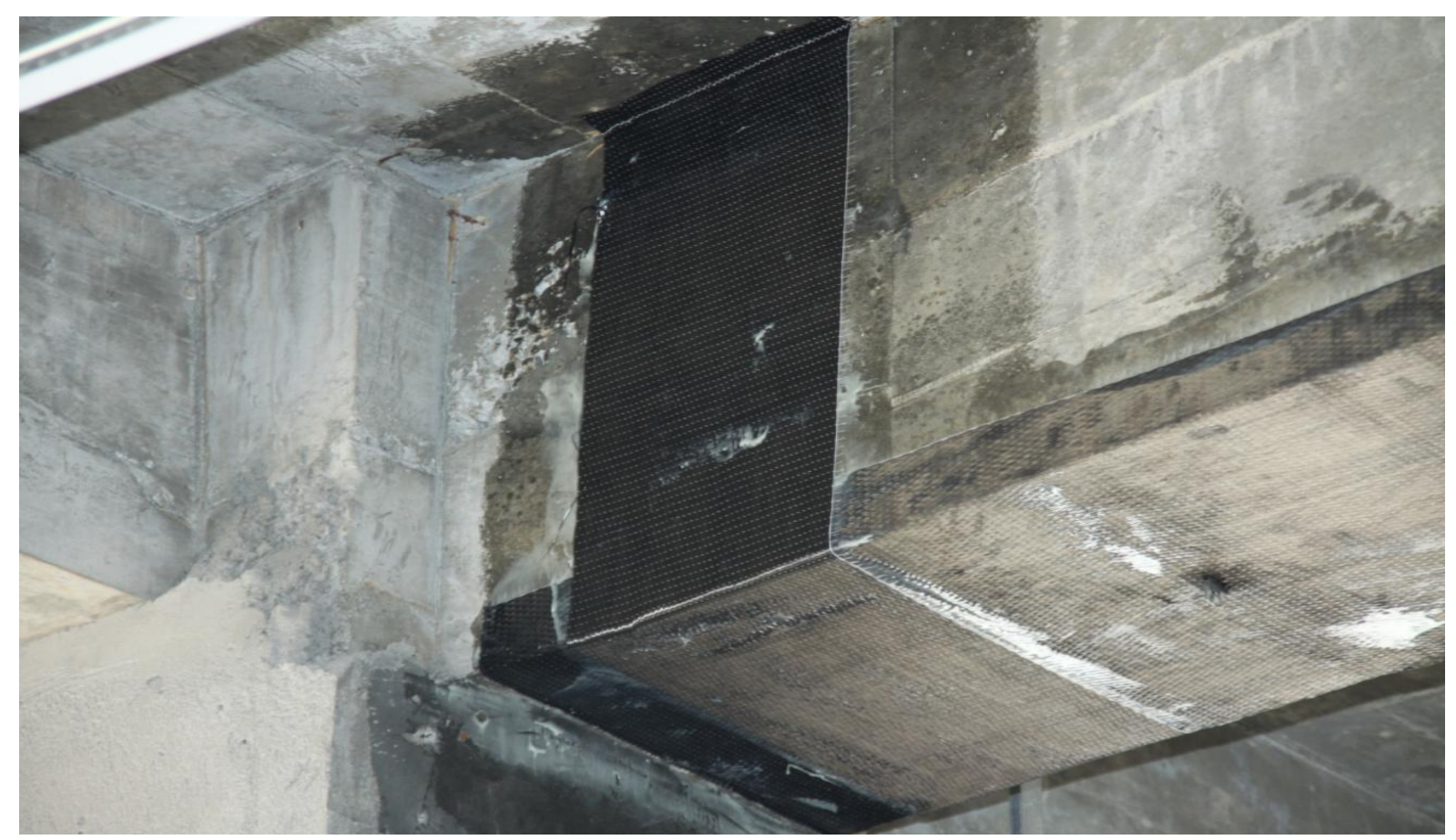

Gambar 5. Wrapping Sika Wrap Hex 230C permukaan beton

6. Curing Time

- Waktu pengeringan Typo Epoxy S 24 jam.

- Temperatur pada saat masa pengeringan harus sesuai dengan ketentuan produsen.

- Permukaan komposit harus mempunyai ketebalan dan kepadatan yang sama dan antar layer harus melekat dengan baik, hal ini ditunjukan dengan tidak adanya celah atau cekungan / udara didalam komposit.

7. Finishing

- Setelah aplikasi permukaan komposit dimungkinkan untuk di cat / diplester. Jika diplester butiran pasir yang lembut harus ditaburkan pada permukaan komposit.

\section{SIMPULAN}

Dari hasil perhitungan dan analisa yang dilakukan terhadap material karbon :

a. Material Sika Wrap Hex 230C bisa digunakan untuk retrofit Bangunan Kantor Gedung Bea dan Cukai Teluk Bayur Padang.

b. Metode pelaksanaan harus benar diperhatikan, agar kekuatan bangunan yang diharapkan kembali seperti semula tahan terhadap gempa.

\section{SARAN}

Perlu diperhatikan sekali dalam memilih metode perkuatan yang akan kita gunakan, agar kondisi kekuatan maksimal bangunan tersebut terpenuhi.

\section{DAFTAR PUSTAKA}

Abdul Rochman, Estimasi Kekuatan Sisa dan Teknologi Perbaikannya, dinamika TEKNIK SIPIL, Volume 6, Nomor 2, Juli 2006 : $94-100$.

Elvi Roza Syofyan,Yurisman, Mukhlis , Tinjauan Kelayakan Struktur Pasar Inpres IV Kodya Padang Pasca Gempa Jurnal Poli Rekayasa vol. VIII No. 1 Oktober $2012: 71-82$.

Irma Aswani Ahmad, Nur Anny Suryaningsih Taufieq, Abdul Hamid Aras, Analisis Pengaruh Temperatur 
terhadap Kuat Tekan Beton, Jurnal Teknik Sipil Vol. 16 No. 2 Agustus 2009: 63 .

SNI 03-2847-2002 tentang Tata Cara Perhitungan Struktur Beton Untuk Bangunan Gedung.

SNI 03-1726-2002 tentang Tata Cara Perencanaan Ketahanan Kebakaran Untuk Bangunan Gedung.

Yurisman \& Elvi Roza Syofyan, Kajian Kelayakan Struktur Bangunan Pasca Gempa (Studi Kasus Gedung Pasar Inpres II Kota Padang) Jurnal Ilmiah REKAYASA SIPIL vol. VIII No. 1 April $2012: 48-55$ 